\title{
Analysis and Evaluation of Development Degree of the Special Township in a Prefecture-level City
}

\author{
Wenrong Jiang and Wenting Shao \\ Shanghai Polytechnic University, School of Computer and Information Engineering, Shanghai, China
}

\begin{abstract}
As a regional economic and social development model based on the construction of towns, the special township is an innovative structure to effectively solve issues on regional development. However, in the process of promoting the construction of special townships, many places have some tendentious problems worthy of attention and vigilance, such as unclear positioning of concept of special townships, increasing risk of development caused by over-indebtedness. Therefore, taking a certain prefecture-level special township in the central part of our country as the example, this article uses the factor analysis model in SPSS Statistics, which depends on the overall development level and development status of the current year, to conduct quantitative analysis of $\mathbf{3 0}$ assessment indicators for 3 major industries and 9 businesses in the special township, so as to assess the existing development advantages and potential development issues, and finally, reasonable and feasible suggestions and countermeasures have been put forward for the future development models and directions.
\end{abstract}

Keywords-special township; development degree; innovative structure; SPSS; factor analysis

\section{INTRODUCTION}

As early as 2014, Zhejiang first proposed the concept of "Special Township". In 2016, the Ministry of Housing and Urban-Rural Development, the National Development and Reform Commission, and the Ministry of Finance jointly issued the "Notice on Developing Special Township Cultivation Work". The notice stated that " by 2020, we will cultivate around 1,000 special and dynamic leisure towns such as leisure travel, trade and logistics, modern manufacturing, educational technology, traditional culture, and beautiful and livable."

The special township studied in this article is located in a certain prefecture-level city in the central region of China. It is one of the two batches of 403 Chinese special townships issued by the Ministry of Housing and Construction. Since July 2016, after the national level development of special townships, relevant departments in the region have actively promoted the creation of special towns.

On the morning of March 28, the 2018 China Special Township Development Forum was held in Beijing. When doing the keynote speech titled "Promoting the Standardized and Orderly Development of Characteristic Towns", Chen Yajun, the director of the Planning Division of the National Development and Reform Commission, pointed out that there have been some tendencies that warrant attention and vigilance in many places in the process of promoting the construction of special townships. It mainly manifested in seven aspects: unclear concept positioning, blind development leading to low quality, homogeneity has no characteristics, government-led marketization is not enough, pay attention to the appearance of the image, blindly increasing debt leads to increased risk,, and excessive participation of housing companies. And some regions even have the risk of intensifying government debt and the signs of real estate.

In order to test the development and construction situation of this special township so far, we respond to the call of the National Development and Reform Commission to prevent the above seven problems, and further positioning of the town's regional economic and social development model to ensure the high quality sustainable development of the special township in the future. Therefore, assessing the current level of development of the special township and quantitatively analyzing the differences in the development of industries in this special township. This paper use factor analysis methods, comprehensive analysis and comparison of the development status of various industries. The result has far-reaching significance for the sustainable development of coordinating the special township.

\section{RESEARCH SitUATION OF DOMESTIC AND ABROAD}

Up to now, a total of 20 provinces have proposed the creation of special townships. The total number of plans has exceeded 1,500. On July 27, 2017, the Ministry of Housing and Urban-Rural Development announced the second batch of 276 special townships. In addition, 127 of the first batch of featured towns announced by the Ministry of Housing and Urban-Rural Development in 2016, and a total of 403 special townships in the country. Combining with the remaining 14 provinces that have not yet announced plans, there will be at least 2,000 provincial-level special townships in the country. These townships will become the reserve forces of the National Thousand Townships Program. The special township has become one of the hottest outlets of the moment. Since it is still in its infancy, its operating model has no trace, and it is good at standardizing the copying and high turnover of housing enterprises, it faces enormous challenges in terms of the development and introduction of industrial factors and the transformation of operational thinking.

Learn the lesson of the past, the teacher of the rear. The presentation of special townships stems from the development experience of major developed countries in the world. In the $1960 \mathrm{~s}$, the rapid development of industrialization and urbanization led to excessive population concentration and 
congestion in large cities. However, hollowing has occurred in the countryside. In order to divide the population of large cities, developed countries have started the construction of special townships. Among them, the urbanization rate reached $70 \%$, when the three countries of the United Kingdom, the United States, and Japan started the construction of special townships. In Korea, the start time is relatively late, and the urbanization rate is between $40 \%$ and $50 \%$, which is close to our country. Up to now, the economic development bodies such as Britain, the United States, South Korea and Japan have all completed the development and cultivation of special townships. Special townships have become the main carriers of economic, demographic and industrial development in these countries.

As the core carrier of population and industry, small cities and towns have become important economic vital points for the balanced development of urban and rural areas in developed countries. For example, in the Silicon Valley where high-tech small towns are clustered in the United States, the population is less than $1 \%$ of the United States, but GDP accounts for $4 \%$ $5 \%$. Napa Valley is a cluster of integrated rural leisure and tourism towns. It receives 5 million domestic and foreign tourists every year. Its tourism economic benefits alone reach 600 million U.S. dollars, and it can provide more than 17,000 job opportunities and tax revenues of 221 million U.S. dollars. The Grasse, France, produces only 600 million euros of wealth every year.

\section{FACTOR ANALYSIS MODEL}

Factor analysis is based on the correlation of indicator variables. First, the variables are grouped. Each group of variables represents a basic structure. It is represented by an unobservable comprehensive variable and is called a public factor. The correlation among the same group of variables is high. The correlation between different groups of variables is lower. Factor analysis aims to avoid losing too much information and study how to use fewer synthetic variables instead of many initial variables, and achieve dimensionality reduction at the same time. The factor analysis model is as follows:

$$
\left\{\begin{array}{c}
X_{1}=a_{11} F_{1}+a_{12} F_{2}+a_{13} F_{3}+\ldots+a_{1 m} F_{m}+\varepsilon_{1} \\
X_{2}=a_{21} F_{1}+a_{22} F_{2}+a_{23} F_{3}+\ldots+a_{2 m} F_{m}+\varepsilon_{2} \\
\ldots \ldots \\
X_{p}=a_{p 1} F_{1}+a_{p 2} F_{2}+a_{p 3} F_{3}+\ldots+a_{p m} F_{m}+\varepsilon_{p}
\end{array}\right.
$$

Abbreviated as: $\mathrm{X}_{\mathrm{px} 1}=\mathrm{A}_{\mathrm{pxm}} \mathrm{F}_{\mathrm{mx} 1}+\varepsilon_{\mathrm{px} 1}$, among them $\mathrm{X}=$ $\left(\mathrm{x}_{1}, \mathrm{x}_{2}, \ldots, \mathrm{x}_{\mathrm{p}}\right)^{\mathrm{T}}$ is a $\mathrm{p}$-dimensional random vector; matrix $\mathrm{A}=$ $\left(a_{i j}\right)_{p x m}$ is the factor loading matrix; $F=\left(F_{1}, F_{2}, \ldots, F_{m}\right)^{T}(m$ $\leq \mathrm{p})$ is the common factor or factor vector; $\mathrm{a}_{\mathrm{ij}}$ is the factor loading, it is the load of the $\mathrm{i}$-th initial variable on the $\mathrm{j}$-th factor; vector $\varepsilon$ is a special factor, it represents the part of the original variable that cannot be explained by the common factor.

The basic idea is to analyze the internal structure of the correlation coefficient matrix of variables, and then find out a few random variables from them, these random variables can control the original variables. The principle of selecting the common factor is to make the common factor contain as much information as possible in the original variable. Modeling $\mathrm{X}=$
$\mathrm{A} \cdot \mathrm{F}+\varepsilon$, ignore $\varepsilon$, replace $\mathrm{F}$ with $\mathrm{X}(\mathrm{m} \leq \mathrm{p})$, and use it to reproduce the correlation between many components $X_{i}(i=1$, $2, \ldots, p)$ of the original variable $X$, to achieve the purpose of simplifying variables and reducing dimensions .

The basic steps of factor analysis in general are as follows:

a. Standardize raw data to eliminate differences in magnitude and dimension between variables

b. Find the correlation matrix of standardized data

c. Finding eigenvalues and eigenvectors of correlation matrices

d. Computational variance contribution ratio and cumulative variance contribution rate

e. Determine the number of factors: Let $F_{1}, F_{2}, \ldots, F_{p}$ be $p$ factors, where the total amount of data information contained in the first $\mathrm{m}$ factors ( their cumulative contribution rate ) is not less than $80 \%$, the first $m$ factors may be taken to reflect the original evaluation index

f. Factor rotation: If the obtained $\mathrm{m}$ factors cannot be determined or its actual significance is not obvious, then the factors need to be rotated to obtain more obvious practical significance

g. Using the linear combination of the original indicators to obtain the scores of each factor, using the regression estimation method, Bartlett estimation method to calculate the score of the factor

h. Total ratings: Taking the variance contribution rate of each factor as the weight, a comprehensive evaluation function is obtained from the linear combination of each factor

i. Sort by score: Use the comprehensive score analysis to get the score ranking

\section{Methodology}

\section{A. Index Selection}

The development industries of the special township are mainly concentrated in these three areas: industry, agriculture, and service industry. Combining the development scale of various industries and the characteristics of the town's industries, nine industries that responded to the comprehensive development capabilities of featured towns were selected as representatives: Stainless Steel, Silkworm Health, Tea Tourism, Environmental Energy, Manufacturing, Creative Agriculture, Clean Energy, Tourism and Leisure, and Non-woven.

Through a comprehensive analysis of the influencing factors of the development of the special township, we then combined the development of various industries. When setting up screening indices, follow the principles of representation, rationality, operability, and comprehensiveness. Using statistical data from the construction of the special township, six indices of the comprehensive development level of the special township were selected as variables from the aspects of economy and society. The followings are as follows: The developed construction area $\left(\mathrm{X}_{1}\right)$, the accumulated investment in fixed assets $\left(\mathrm{X}_{2}\right)$, the number of settled companies $\left(\mathrm{X}_{3}\right)$, the 
number of enterprises settled above designated size $\left(\mathrm{X}_{4}\right)$, the total number of employees at the end of the period $\left(\mathrm{X}_{5}\right)$, and the main business income of all enterprises $\left(\mathrm{X}_{6}\right)$.

\section{B. Index Process}

Using the factor analysis method in SPSS 22 software, six data indices were analyzed. The KMO and Bartlett tests were first performed to determine whether the data were suitable for factor analysis. The results are shown in Table I.

\section{TABLE I. KMO AND BARTLETT'S TEST}

\begin{tabular}{|l|c|c|}
\hline \multicolumn{2}{|c|}{ KMO and Bartlett's Test } \\
\hline $\begin{array}{l}\text { Table column subhead Kaiser-Meyer-Olkin Measure of } \\
\text { Sampling Adequacy }\end{array}$ & 0.574 \\
\hline \multirow{3}{*}{ Bartlett's Test of Sphericity } & Approx. Chi-Square & 58.078 \\
\cline { 2 - 3 } & df. & 15 \\
\cline { 2 - 3 } & Sig. & 0.000 \\
\hline
\end{tabular}

Table I shows that the value of KMO is 0.574 , and the value of KMO statistic is greater than 0.5; the Bartlett spherical test statistic in the table is 68.078 , and the phase probability $p$ is 0 , which is less than the significance level 0.01 . It indicates that the partial correlation coefficient can be rejected as 0 , and the original assumption that the correlation coefficient matrix is a unit matrix can be rejected. This shows that there is a complex statistical correlation between variable indicators, indicating that the selected data can be used for factor analysis.

Before performing factor analysis, the initial variable observation data needs to be standardized first, in order to eliminate the influence of dimension and magnitude differences on the analysis results. Since the indicator's value is normalized the average level is 0 , so the subsequent analysis results will have positive or negative values. A positive value indicates that the result is higher than the average level, and a negative value indicates that the result is lower than the average level.

\section{The Extraction of Factors}

The data of six indices are processed, which can reflect the development degree of each special township's various industries. Find out the common factor special values, variance contribution rates, and cumulative variance contribution rates. The results are shown in Table II and Table III.
TABLE II. TOTAL VARIANCE EXPLAINED

\begin{tabular}{|c|c|c|c|c|c|c|}
\hline \multirow{2}{*}{ Factors } & \multicolumn{3}{|c|}{ Initial Eigenvalues } & \multicolumn{2}{c|}{$\begin{array}{c}\text { Extraction Sums of Squared } \\
\text { Loadings }\end{array}$} \\
\cline { 2 - 7 } & Total & $\begin{array}{c}\text { \% of } \\
\text { Variance }\end{array}$ & $\begin{array}{c}\text { Cumulative } \\
\%\end{array}$ & Total & $\begin{array}{c}\text { \% of } \\
\text { Variance }\end{array}$ & $\begin{array}{c}\text { Cumulative } \\
\%\end{array}$ \\
\hline 1 & 4.062 & 67.692 & 67.692 & 4.062 & 67.692 & 67.692 \\
\hline 2 & 1.165 & 19.415 & 87.107 & 1.165 & 19.415 & 87.107 \\
\hline 3 & 0.709 & 11.812 & 98.920 & & & \\
\hline 4 & 0.040 & 0.660 & 99.579 & & & \\
\hline 5 & 0.020 & 0.340 & 99.919 & & & \\
\hline 6 & 0.005 & 0.081 & 100.000 & & & \\
\hline
\end{tabular}

TABLE III. ROTATED FACTORS

\begin{tabular}{|c|c|c|c|}
\hline Factors & $\begin{array}{c}\text { Special } \\
\text { Value }\end{array}$ & $\begin{array}{c}\text { The percentage of } \\
\text { variance }\end{array}$ & $\begin{array}{c}\text { The total percentage of } \\
\text { variance }\end{array}$ \\
\hline 1 & 3.786 & 63.106 & 63.106 \\
\hline 2 & 1.440 & 24.001 & 87.107 \\
\hline
\end{tabular}

From Table II and Table III, it can be seen that the special values of the variable correlation coefficient matrix of these two factors are greater than one. The percentage of the first factor $\mathrm{F} 1$ is $63.106 \%$, the percentage of the second factor F2 is $24.001 \%$, and the cumulative variance contribution rates arrived at $87.107 \%$, indicating that the two factors contain $87.107 \%$ of the original information. According to the general principle that the cumulative variance contribution rate is greater than $85 \%$, the information represented by these two factors can fully explain and provide the information expressed by the original data.

TABLE IV. LOADED INDICES IN THE FACTORS

\begin{tabular}{|c|c|c|}
\hline \multirow{2}{*}{ Indices } & \multicolumn{2}{|c|}{ Factors } \\
\cline { 2 - 3 } & $\boldsymbol{F}_{\boldsymbol{1}}$ & $\boldsymbol{F}_{\boldsymbol{2}}$ \\
\hline $\mathrm{X}_{2}$ & 0.991 & 0.069 \\
\hline $\mathrm{X}_{6}$ & 0.980 & 0.146 \\
\hline $\mathrm{X}_{5}$ & 0.963 & 0.143 \\
\hline $\mathrm{X}_{4}$ & 0.925 & 0.324 \\
\hline $\mathrm{X}_{1}$ & 0.026 & 0.878 \\
\hline $\mathrm{X}_{3}$ & 0.247 & 0.719 \\
\hline
\end{tabular}

The original data load matrix is established for the two extracted factors, and the rotation load matrix is obtained by analyzing the maximum orthogonal rotation method of variance. The results are shown in Table IV. The higher the value of the factor load, the higher the degree of correlation between the index and the factor. Meanwhile, indicating the greater the amount of information contained in this factor. From the factor load matrix in Table IV, it is found that the first factor has significant load on the four indices of various industries. And the loaded values are all above 0.9. These indices include the accumulated investment in fixed assets $\left(\mathrm{X}_{2}\right)$, the number of enterprises settled above designated size $\left(\mathrm{X}_{4}\right)$, 
and the total number of employees at the end of the period $\left(\mathrm{X}_{5}\right)$, and the main business income of all enterprises $\left(\mathrm{X}_{6}\right)$.This shows that $F_{1}$ has concentrated on the development of strength in various sectors such as capital strength, company size, and talent recruitment. Therefore, the first factor is named as the comprehensive development strength factor, and can explain $63.106 \%$ of the variance. The second factor has a larger load on the developed construction area $\left(\mathrm{X}_{1}\right)$ and the number of settled companies $\left(\mathrm{X}_{3}\right)$, and the loaded values are all above 0.7 . It mainly reflects the degree of development and construction of various industries. Therefore, the $\mathrm{F}_{2}$ is named development and construction degree factor, and it can explain $24.001 \%$ of the variance.

\section{Rank of Scores}

The SPSS 22 software calculates the factor scores of the two factors. The weighted average can be weighted by using the variance contribution rate of each factor as the weight. Use the formula below to define the total scores for each industry:

$$
F=\left(63.106 \times F_{1}+24.001 \times F_{2}\right) / 87.107
$$

Then according to the F1 scores, the F2 scores and the total scores, the various industries in the town were ranked separately. The results are shown in Table V.

In order to visually see the links and gaps between the individual scores on the two factors and the total factor scores for each industry in the special township. With the score ranking as the ordinate and the industry category as the abscissa, convert the above table into a histogram (Figure I).

TABLE V. THE SCORES AND RANKS OF EACH INDUSTRY IN THE SPECIAL TOWNSHIP

\begin{tabular}{|c|c|c|c|c|c|c|c|}
\hline \multirow{2}{*}{ Industries } & \multirow{2}{*}{ Categories } & \multicolumn{2}{|c|}{$\mathbf{F}_{\mathbf{1}}$} & \multicolumn{2}{|c|}{$\mathbf{F}_{\mathbf{2}}$} & \multicolumn{2}{c|}{ F $_{\mathbf{3}}$} \\
\cline { 3 - 8 } & & Score & Rank & Score & Rank & Score & Rank \\
\hline Stainless Steel & Industry & 2.64651 & 1 & -0.12673 & 4 & -0.12673 & 1 \\
\hline Manufacturing & Industry & -0.09103 & 2 & 1.72128 & 1 & 1.72128 & 2 \\
\hline Creative Agriculture & Agriculture & -0.40493 & 7 & 1.60578 & 2 & 1.60578 & 3 \\
\hline Silkworm Health & Agriculture & -0.26673 & 4 & 0.07218 & 3 & 0.07218 & 4 \\
\hline Non-woven & Industry & -0.30057 & 5 & -0.58336 & 7 & -0.58336 & 5 \\
\hline Tourism and leisure & Service & -0.39994 & 6 & -0.38967 & 5 & -0.38967 & 6 \\
\hline Clean Energy & Industry & -0.24594 & 3 & -1.0575 & 9 & -1.0575 & 7 \\
\hline Environmental Energy & Industry & -0.50399 & 9 & -0.45414 & 6 & -0.45414 & 8 \\
\hline Tea Tourism & Service & -0.43336 & 8 & -0.78783 & 8 & -0.78783 & 9 \\
\hline
\end{tabular}

\section{Ranks}
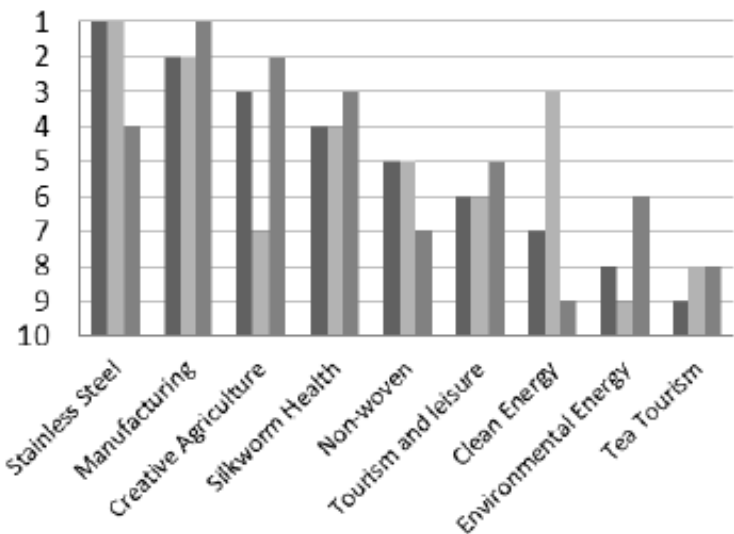

Industries

- F:Total Factor

n F1:Comprehensive Development Strength Factor

n F2:Development and Construction Degree Factor

FIGURE I.COMPREHENSIVE RANKS

\section{CONCLUSIONS}

According to the total ranking of the development level of each industry in the special townships, the top three are Stainless Steel, Manufacturing and Creative Agriculture. This shows that the current comprehensive development of these industries is in good condition. It is not difficult to find that these industries belong to the primary industry and the secondary industry. In particular, Stainless Steel and Manufacturing are old traditional industries. And they are the pillar industries of the town for a long time.

The last three are Clean Energy, Environmental Energy and Tea Tourism. This shows that the current development degree of these industries is at a low level. However, it does not mean that the development of these industries is very poor. Although Clean Energy, Environmental Energy, and the top two Stainless Steel and Manufacturing industries belong to the same industry. What is different is that Clean Energy and Environmental Energy are "National Strategic Emerging Industries." This will be the country's key development direction, major development tasks, and supporting industries in the next decade. Therefore, it is concluded that the special township is still in the initial stage of transition from traditional industries to 
emerging industries. Traditional industries remain the main economic pillar of the town, and emerging industries are at an early stage.

The rank of the two factor scores and the total scores are not exactly the same. For example, Creative Agriculture ranked third in the total scores. However, it only ranked seventh in the $F_{1}$ score (comprehensive development strength factor score). This rank is 4 points behind the total score. However, Creative Agriculture ranked second in the $\mathrm{F}_{2}$ score (development and construction degree factor score), and it is also higher than the total score rank. This shows that Creative Agriculture has a certain degree of development and construction, and there is sufficient development and construction area. There are also quite a few companies involved in the field of Creative Agriculture. As far as comprehensive development strength is concerned, as a new type of modern agriculture, Creative Agriculture is still not comparable to the mature agriculture of Silkworm Breeding. But the future development prospects cannot be underestimated.

Different factor scores represent the strengths and weaknesses of the industry's development status in a certain aspect. For example, although Clean Energy is ranked third in the total score, and in the development and construction degree factor $\left(\mathrm{F}_{2}\right)$, it is also ranked last. However, it was at a good level in the comprehensive development strength factor $\left(\mathrm{F}_{1}\right)$, ranking third. It shows that, in the one hand, Clean Energy has a low level of development and construction. In the other hand, based on the existing development and construction, the comprehensive development strength is strong. Based on this situation, we can consider further speeding up the development and construction and increase the investment of funds.

Therefore, from the results of factor analysis, it can be clearly seen that special township is in the transformation stage from "old" to "new".

In industrial development, the town is in the transition phase of primary industry. There are old traditional industries such as Stainless Steel and Manufacturing as economic support, and new industries have gradually grown. In particular, the evaluation performance of the Clean Energy in the comprehensive development strength shows that the special township has achieved initial results in the development of emerging industries. Although emerging industries have a low level of development and construction. However, the development strength is full of potential and there is ample room for development.

In agricultural transformation, the agricultural reforms have achieved remarkable results. Modern agriculture represented by Creative Agriculture and Silkworm Health has been at the upstream level in the total ranking of all industries. However, the gap between the comprehensive development strength $\left(\mathrm{F}_{1}\right)$, the development and construction degree $\left(\mathrm{F}_{2}\right)$, and the total factor ranking of Creative Agriculture can reflect the existence of excessive development and construction. Blind development and construction areas lead to heavy development burdens. And it caused the development strength not catch up with the development speed. As a result, the comprehensive development strength has declined. Faced with this situation, we can further introduce high-end technical talents to enhance our development strength.

The overall service industry is located in the middle and lower reaches, whether in the individual rankings of the common factors or in the overall rankings. So the town's service industry is in its infancy. The service industry belongs to the third industry that the country is vigorously developing. As China gradually approaches the development goal of a welloff society, the proportion of the tertiary industry in all industries will continue to rise. Accelerating the development of the tertiary industry and transforming the mode of economic development will also be the inevitable trend in the future.

\section{FURTHER SUGGESTIONS}

In combination with the above factor analysis results, each field category should timely adjust the focus of development investment according to its own characteristics. At the same time, all industries must strive to raise the level of comprehensive development. In the same category, the topranking industries should increase their support for vulnerable emerging industries on the basis of maintaining their own development level. The industries that rank behind must summarize and analyze the causes and find out the strengths and weaknesses. They should use their own advantages to drive disadvantages, thereby increasing the overall level of development. Relevant departments may consider assisting vulnerable industries and appropriate policy assistance. In each category, the "new" and "old" transformations of various industries can be carried out in an orderly manner, enabling the special township to smoothly transition from the "old" to "new" transitional stages.

\section{ACKNOWLEDGEMENT}

This work is supported by the Key Disciplines of Computer Science and Technology of Shanghai Polytechnic University under Grant No. XXKZD1604.

\section{REFERENCES}

[1] Wenrong Jiang. Analysis the $\mathrm{O} 2 \mathrm{O}$ marketing model about old network website[J]. The Second International Conference on Economic and Business Management (FEBM2017), Shanghai, China, ATLANTIS Press. October 21-23, 2017, 507-512.

[2] Fatemeh Shahriar, Mehdi Momeni, Majid Montazeri, and Alireza Freidooni, "Evaluating the development degree of qazvin province counties using the factor and cluster analysis", Canadian Center of Science and Education, Asian Social Science, vol. 11, 2015.

[3] Wenrong Jiang, Yingyan Liu. Analysis of the double 11 ouyeel business promotion effectiveness[C]. 2016 ISSGBM International Conference on Information, Communication and Social Sciences (ISSGBM-ICS 2016), Dubai, United Arab Emirates, Singapore Management and Sports Science Institute, October 8, 2016, 49-55. WOS:000391774900010

[4] Wenrong Jiang, Ying Zhang. E-commerce Planning and Implementation of SELOT ENVIRONMENT Co., LTD.[C]. 2016 International Conference on Education \& Educational Research and Environmental Studies (EERES 2016), Hong Kong, DEStech Publications, Inc. September 3, 2016, 102-106. WOS:000403805600027M.

[5] Sweet, Stephen A., Grace-Martin, Karen, Data analysis with SPSS, 2nd ed., Allyn \& Bacon, 2010

[6] Wenrong Jiang. The Analysis of SEO from Jumei Youpin's Crash[J]. The 2017 International Conference on Applied Mechanics and 
Mechanical Automation(AMMA2017), HongKong, China, DEStech Publications, Inc. June 23, 2017, 401-405.

[7] Wenrong Jiang. Analysis of B2B E-commerce Development With a Case Study of Made-in-China Website[J]. 4th International Conference on Business, Education, Law and Interdisciplinary Studies(BELIS 2017), London, UK, June 29, 2017, 130-135.

[8] Taghvael, I.Bahari, "Assessing development degree and ranking townships of mazandaran province by using factor analysis and cluster analysis", Geography and Environmental Planning Journal, vol. 48, 2013.

[9] Nancy L. Leech, Karen C. Barrett, George A. Morgan, IBM SPSS for Intermediate Statistics: Use and Interpretation, 5th ed., vol. 1, Routledge, 2014 